\title{
Multi-instrument Observations of Ion-Neutral Coupling in the Dayside Cusp
}

\author{
D. D. Billett ${ }^{1}$, K. Hosokawa ${ }^{2}$, A. Grocott ${ }^{1}$, J. A. Wild ${ }^{1}$, A. L. Aruliah ${ }^{3}$, Y. \\ Ogawa $^{4}$, S. Taguchi ${ }^{5}$, M. Lester ${ }^{6}$ \\ ${ }^{1}$ Physics Department, Lancaster University, Bailrigg, Lancaster, LA1 4YB, United Kingdom. \\ ${ }^{2}$ University of Electro-Communications, Chofu, Tokyo, 182-8585, Japan \\ ${ }^{3}$ Department of Physics and Astronomy, University College London, Gower Street, London, WC1E 6BT, \\ United Kingdom. \\ ${ }^{4}$ National Institute of Polar Research, Tachikawa, Tokyo, 190-0014, Japan \\ ${ }^{5}$ Graduate School of Science, Kyoto University, Kyoto, 606-8502, Japan \\ ${ }^{6}$ Department of Physics and Astronomy, University of Leicester, University Road, Leicester, LE1 7RH, \\ United Kingdom.
}

\section{Key Points:}

- Ion-neutral coupling near the dayside cusp is examined during an interval of enhanced auroral activity.

- Neutral wind re-orientation occurs much faster during enhanced particle precipitation, causing a pseudo-coupling to the solar wind.

- Instead of being enhanced by increased auroral conductivity, Joule heating is dampened by the neutral winds.

Corresponding author: D. D. Billett, d.billet@lancaster.ac.uk 


\begin{abstract}
Using data from the Scanning Doppler Imager, the Super Dual Auroral Radar Network, the EISCAT Svalbard Radar and an auroral all-sky imager, we examine an instance of F-region neutral winds which have been influenced by the presence of poleward moving auroral forms near the dayside cusp region. We observe a reduction in the time taken for the ion-drag force to re-orientate the neutrals into the direction of the convective plasma (on the order of minutes), compared to before the auroral activity began. Additionally, because the ionosphere near the cusp is influenced much more readily by changes in the solar wind via dayside reconnection, we observe the neutrals responding to an interplanetary magnetic field change within minutes of it occurring. This has implications on the rate that energy is deposited into the ionosphere via Joule heating, which we show to become dampened by the neutral winds.
\end{abstract}

\title{
1 Introduction
}

In the thermosphere, neutrals are under the influence of forces from numerous sources. Near the equator, horizontal motion is nearly entirely dayside to nightside directed (Jacchia, 1965) and is limited in velocity due to drag imparted from collisions with locally ionised particles. At higher geomagnetic latitudes however (typically $>60^{\circ}$ ), where ions are set into motion due to the large scale Dungey cycle convection (Dungey, 1961), both the global and mesoscale behaviour of the neutrals becomes much more complicated.

The high latitude plasma convection is generally much faster than the neutral wind, regularly reaching over $1 \mathrm{~km} \mathrm{~s}^{-1}$ (Ruohoniemi et al., 1987). As such, the ion drag force acts to accelerate the neutrals into the $\mathbf{E} \times \mathbf{B}$ direction. This is clear both statistically (e.g. Förster et al., 2008) and in case studies (e.g. Conde \& Smith, 1998). In general, the average polar neutral wind pattern resembles the average plasma convection pattern. However, average conditions of both are not generally representative of mesoscale phenomena. The plasma convection can for instance be quite variable, and respond very quickly to changes in the interplanetary magnetic field (IMF) (Murr \& Hughes, 2001). This is especially true on the dayside, where reconnection processes propagate quickly into the cusp region.

Of course, ion-drag is not the sole force acting on the high latitude neutral wind. Temperature gradients between the dayside and nightside in particular still drive neu- 
trals anti-sunward as they do at lower latitudes. This, and other effects with lesser influence (such as Coriolis and viscous forces) deviate the neutral wind further from perfect coupling to the plasma, contributing to its sluggishness in responding to changes in the convection (e.g. a large change in solar wind driving). Thus, there are often large delays (on the order of hours) before velocity changes in the high latitude plasma translate fully into the neutral wind (e.g. Billett et al., 2019). Traditionally, a quantitative time delay is determined by calculating the time for the neutral wind to accelerate to 1/e of the plasma velocity (e.g. Kosch et al., 2001).

The neutral acceleration is described by the momentum equation (e.g. Rishbeth, 1972), of which the ion-drag component is given by:

$$
a_{d r a g}=\nu_{n i}(\mathbf{u}-\mathbf{v})
$$

where $\mathbf{u}$ and $\mathbf{v}$ are the neutral and plasma velocities respectively, and $\nu_{n i}$ is the neutralion collision frequency. In the F-region, the thermosphere is weakly ionised and so $\nu_{n i}$ is small (about $1 \mathrm{~Hz}$ compared to $1 \mathrm{kHz}$ in the E-region; Pfaff, 2012). However, ionisation due to particle precipitation can modify this significantly by increasing plasma density and in turn, strengthen collisions and ion drag acceleration. This would decrease the acceleration timescale of the neutral wind to changes in the plasma. In fact, recent studies (Conde et al., 2018; Zou et al., 2018) have certainly shown this to be the case, observing a rapid ( $<20$ minutes) neutral wind response during auroral activity. This is much shorter than previous estimations (on the order of a few hours) during periods of little or no precipitation (Kosch et al., 2010; Joshi et al., 2015; Billett et al., 2019).

In contrast to those previous authors, who observe events in the nightside auroral zone, the higher latitude of Svalbard allows for observations of the dayside cusp region. In this locale, the ionosphere is influenced more readily by changes in the solar wind via dayside reconnection, than by substorm processes on the nightside. With F-region data from the Super Dual Auroral Radar Network (SuperDARN), the Scanning Doppler Imager (SCANDI), the EISCAT Svalbard Radar (ESR) and an all-sky auroral imager, we examine a cusp region event on December 12th, 2013, that reveals a thermosphere experiencing two very different regimes of ion-drag forcing. A series of poleward moving auroral forms (PMAF: Fasel, 1995) was seen which drove dynamic changes to the thermospheric wind, contrasting significantly to the quiet period shortly before the aurora were observed. We also investigate the nature in which the neutrals modify Joule 
heating rates during this event, so as to assess their importance in comparison to statistics (Billett et al., 2018).

\section{Instrumentation}

\subsection{Neutral Winds and Neutral Temperatures}

SCANDI (Aruliah et al., 2010) is a wide field Fabry-Perot interferometer located at Longyearbyen, Svalbard $\left(78.15^{\circ}, 16.04^{\circ}\right.$ geographic, $75.52^{\circ} 108.21^{\circ}$ Altitude-adjusted corrected geomagnetic (AACGM); Shepherd (2014)), and can be used to spatially resolve neutral wind vectors within a field of view (FOV) of approximately $1000 \mathrm{~km}$ diameter, as well as the neutral temperatures. An image of the sky is sub-divided into several zones, in each of which an individual Doppler spectrum is measured. From these, neutral wind vectors and temperatures with a horizontal resolution of approximately 100$200 \mathrm{~km}$ near altitudes of $250 \mathrm{~km}$ are determined when a 61 zone grid is used. This procedure is described in more detail by Aruliah et al. (2010). The exposure/integration time of one SCANDI derived neutral wind field is approximately 7.5 minutes.

\subsection{Plasma Convection}

The SuperDARN consists of 35 HF radars situated in both hemispheres that measure the line of sight Doppler velocity of field aligned plasma irregularities. Velocities from all radars in the same hemisphere are gridded together, and typically supplemented by a statistical model based on IMF conditions to account for regions of poor data coverage. A spherical harmonic function is then fitted to create a map of electrostatic potential (Ruohoniemi \& Baker, 1998), which is a direct representation of the Dungey cycle convection pattern. For the event presented in this study, the statistical model by Thomas and Shepherd (2018) and all available data in the northern hemisphere is integrated over two-minute intervals. The two radars with fields of view overlooking Svalbard are those at Hankasalmi, Finland and Pykkvibaer, Iceland; both of which obtained un-interrupted measurements within the SCANDI field of view for the event described in this study.

\subsection{Auroral Intensity and Electron Density}

$630 \mathrm{~nm}$ auroral intensities, corresponding to an emission altitude of approximately $250 \mathrm{~km}$, were obtained from an all-sky imager (Taguchi et al., 2012) which is co-located 
with SCANDI on Svalbard. During the event described in this study, both $1 \mathrm{~s}$ and $4 \mathrm{~s}$ exposures were taken sequentially. However, the auroral brightness was so high at times that the $4 \mathrm{~s}$ images were occasionally over-saturated. Therefore, only the $1 \mathrm{~s}$ exposures were used.

Later in this paper, we relate the $630 \mathrm{~nm}$ auroral intensities directly to the F-region Pedersen conductivity by using electron density data from the ESR. Data from only the $42 \mathrm{~m}$ dish was used, which is aligned parallel to the terrestrial magnetic field and lies within the FOV of both SCANDI and the all-sky imager

\section{Results}

The event of interest occurred on the 8th December, 2013, of which an overview is shown in Figure 1. During this time, the IMF $B_{\mathrm{z}}$ was almost always southward apart from a 15 minute interval beginning at 07:40UT. The IMF $\mathrm{B}_{\mathrm{y}}$ began negative, turns strongly positive slightly before 07:00UT and then decreased significantly in magnitude by 09:00UT. The aurora began at 07:30UT, around 10 minutes before the northward $\mathrm{B}_{\mathrm{z}}$ transition. Prior to this, the auroral oval was equatorward of the FOV and hence the keogram was dark. The PMAFs were characterised by bright, short-lived 630nm intensity bursts, first at 07:45 UT, stretching between $71^{\circ}$ and $76^{\circ}$ magnetic latitude. The PMAFs continued throughout the brief period of northward $\mathrm{B}_{\mathrm{z}}$ and until 08:30UT, when both $\mathrm{B}_{\mathrm{z}}$ and $\mathrm{B}_{\mathrm{y}}$ decreased in magnitude. The main auroral oval then sat at approximately $75^{\circ}$ magnetic latitude (at a much dimmer intensity), and at 09:00UT, there were further bright enhancements that had a similar latitudinal extent as the PMAF.

To show the effect of PMAF on the ionospheric electron density, two ESR experiments with differing time integrations were running for the event presented in this study. The $30 \mathrm{~s}$ "Beata" experiment and the $60 \mathrm{~s}$ "Taro" experiment. Beata was in operation until 06:57 UT, while Taro was from 07:11 UT onwards. Initially, $n_{e}$ was fairly uniform above $300 \mathrm{~km}$ with time, and the greatest ionisation was present above $200 \mathrm{~km}$ altitude. After the PMAF began, large and short-lived $n_{e}$ enhancements which spanned from 100$600 \mathrm{~km}$ altitude occurred whenever the corresponding $630 \mathrm{~nm}$ bursts crossed the ESR beam. Increased ionisation continues after the PMAF while the auroral oval remained at the ESR latitude until 09:20UT. 

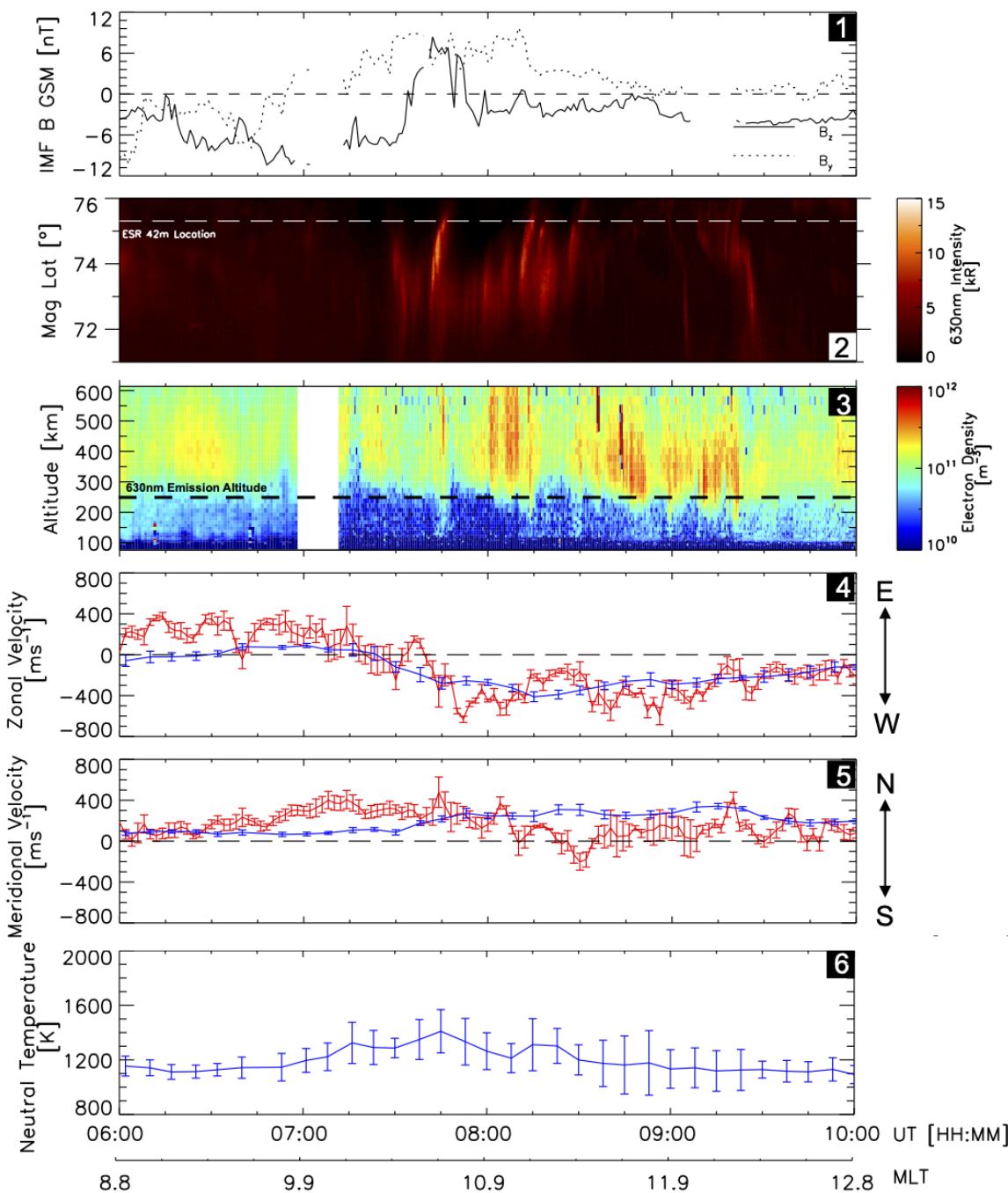

Figure 1. Overview of the 8th December 2013 event. 1: The IMF $B_{\mathrm{z}}$ and $\mathrm{B}_{\mathrm{y}}$ components (OMNI dataset, lagged to the dayside ionosphere). 2: Auroral $630 \mathrm{~nm}$ intensity keogram (Svalbard all-sky imager). 3: Altitude-time plot of the electron density (ESR $42 \mathrm{~m}$ beam). 4: Average zonal and 5: meridional velocity components of the neutrals (blue, SCANDI) and plasma (red, SuperDARN). 6: Average neutral temperatures from SCANDI. The zonal and meridional velocities, and the neutral temperatures, are averages between $71^{\circ}$ and $76^{\circ}$ magnetic latitude within the SCANDI FOV. Error bars on 4, 5 and 6 are standard deviations.

Velocity component averages for both the plasma and neutral flows were calculated using neutral and plasma vectors from each of the SCANDI zones below $76^{\circ}$ magnetic latitude (approximately half the FOV), to match the region of auroral activity. The plasma 
flow began eastward while the IMF $\mathrm{B}_{\mathrm{y}}$ was negative. Then, when $\mathrm{B}_{\mathrm{y}}$ became positive before 07:00UT, the plasma flow quickly turned westward. In contrast, the neutral flow began weakly westward and turned eastward by 07:00UT. They began turning westward again to match the new plasma flow direction from 07:00UT to 07:15UT, but then sped up considerably after the PMAF started. The neutral flow changed direction only a few minutes after the plasma flow, and both reached a maximum westward velocity at approximately the same time, 20 minutes after the $\mathrm{B}_{\mathrm{y}}$ transition. For the remainder of the auroral activity, the average zonal component of the neutral and plasma flow remained fairly similar.

For the meridional components, both the plasma flow and neutral wind started with a similar poleward velocity. Between 06:20-07:10UT however, the plasma accelerated to $400 \mathrm{~ms}^{-1}$ poleward (coinciding with $\mathrm{B}_{\mathrm{z}}$ becoming more negative). The neutral velocity started to increase in the same direction between 07:00-07:15UT, 40-55 minutes after the plasma velocity began to accelerate. When the PMAF began at about 07:30UT, the neutral wind accelerated from $100 \mathrm{~ms}^{-1}$ to $300 \mathrm{~ms}^{-1}$ within 20 minutes and stayed fast for the remainder of the event. The plasma however reduced in meridional velocity from around 08:00UT, and became primarily zonal.

Initially, $T_{n}$ hovered around $1150 \mathrm{~K}$ between 06:00UT and 06:50UT with relatively small standard deviations. There was then an increase coinciding with the aforementioned $B_{y}$ transition from negative to positive, reaching a peak $T_{n}$ of $\sim 1450 \mathrm{~K}$ around 07:45UT. Standard deviations at this time were larger than before, but still small enough to distinguish a clear temperature enhancement. $T_{n}$ from here on gradually decreased back to initial levels by the end of the event, although the spread of temperatures became large between 08:30UT and 09:00UT.

To provide context for the horizontal neutral wind and plasma morphologies, Figure 2 shows nine snapshots of the neutral wind fields, $630 \mathrm{~nm}$ intensities and electric potential contours mapped onto MLAT-MLT coordinates between 06:45 and 07:45UT. Each panel is a sequential SCANDI integration period, with the $630 \mathrm{~nm}$ intensity and plasma convection pattern corresponding to the start of the period. It is important to recall here that the integration time of the neutral winds is comparable to, or even longer than, the duration of a single PMAF pulse, which induces a margin of error when trying to de- 

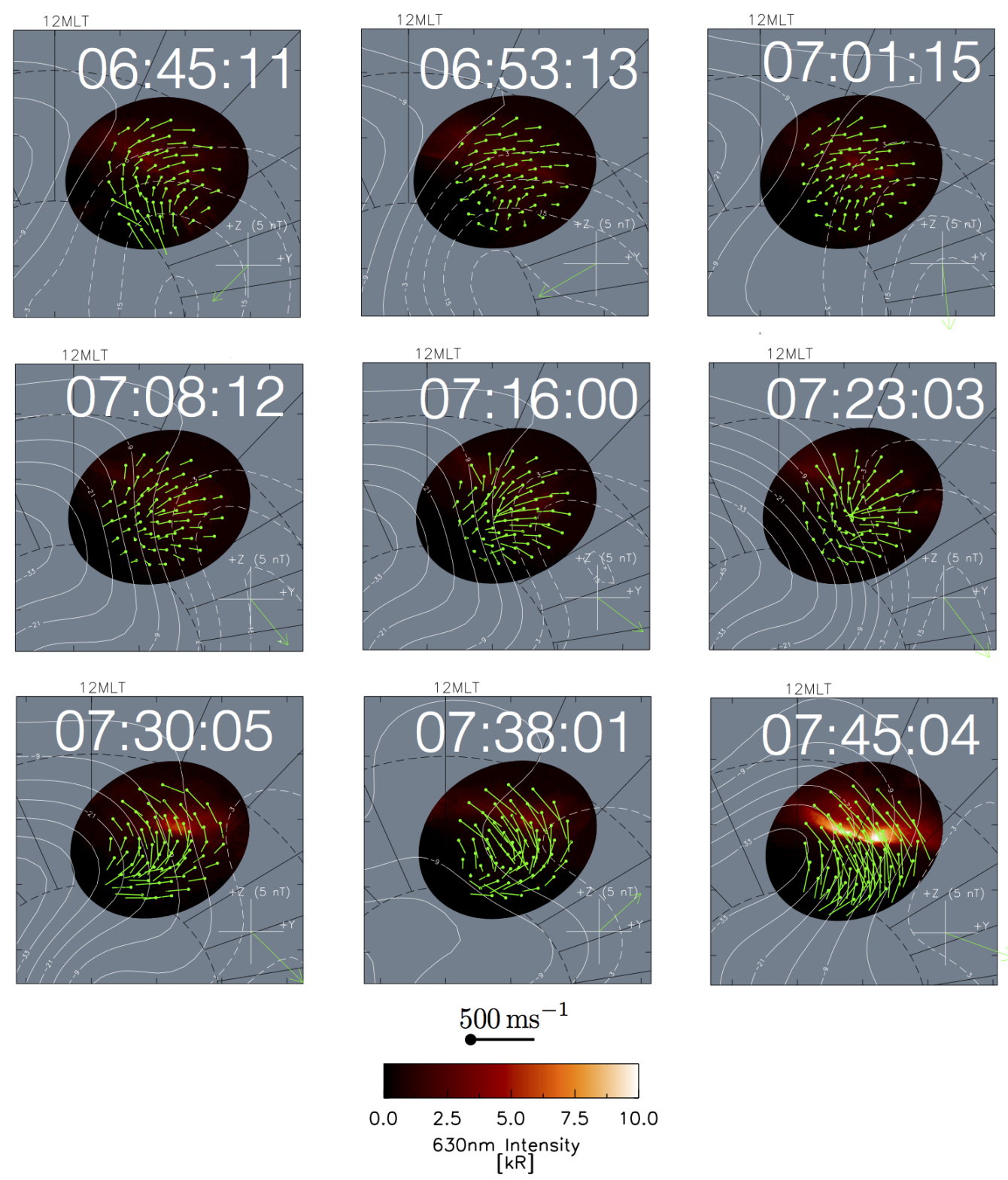

Figure 2. Zoomed in MLAT-MLT (in AACGM coordinates, noon top and dawn right) plots of neutral winds (green vectors), 630nm intensity (red-white colour) and electric potential (white contours) between 06:45:11 and 07:45:04UT. Dashed black lines are constant AACGM latitudes, separated by $10^{\circ}$. Radial solid black lines indicate whole hours of MLT.

termine the cause of any neutral wind changes, up to the length of the SCANDI integration period.

The most striking aspect of the neutral winds during this period is how quickly they re-orientated after the transition from negative to positive $\mathrm{B}_{\mathrm{y}}$. In the panel before the 
$\mathrm{B}_{\mathrm{y}}$ transition (06:53:13), SCANDI was located in the dawn convection cell, close to the dayside convection reversal boundary, and the neutral wind on the poleward side had turned from eastward to westward. By 07:08:12, there was a strong positive $\mathrm{B}_{\mathrm{y}}$ component and the convection pattern shifted such that SCANDI was located between the two cells. The plasma flow was mostly poleward with a small westward component, while the neutral flow remained eastward. Until 07:30:05, the convection within the SCANDI FOV gradually became more westward. Sometime between the integration period starting at 07:30:05 and ending at 07:38:01, the neutral wind switched direction, aligning more closely with the convection, and coinciding with the $630 \mathrm{~nm}$ brightening. The convection was disturbed, but still mainly poleward, during the northward IMF period at 07:38:01UT. For the remaining duration of the PMAF, SCANDI moved further into the dusk cell where the plasma flow was primarily westward on the equatorward side, but poleward on the poleward side of the FOV. The neutral wind then roughly followed the contours of convection.

\section{Discussion}

We have presented evidence for much stronger coupling of the thermosphere to the ionosphere in the presence of PMAFs, compared to when they were absent. PMAFs are the result of open field lines moving poleward across the dayside ionosphere while energetic particles are deposited from the solar wind, generating bright aurora near noon (Fasel, 1995). We saw these between 07:30 and 08:30UT (10.4-11.4MLT) in the auroral data, which is slightly dawnward of typical PMAF onset location (noon MLT), and was likely due to the strongly positive IMF $\mathrm{B}_{\mathrm{y}}$ causing dayside reconnection to be offset from the magnetopause (Cooling et al., 2001). PMAF occurring during northward $\mathrm{B}_{\mathrm{z}}$, which we saw from 07:40-07:55UT, has been noted as a somewhat uncommon occurrence (McWilliams et al., 2000), but more likely during strong $\mathrm{B}_{\mathrm{y}}$ conditions such as here (Fear et al., 2005). The auroral activity which occurred from 09:00-09:30UT is a signature of so-called "throat aurora", which has recently come to prominence (Han et al., 2017).

Because the electron density enhancements at lower altitudes correspond exactly with the PMAFs crossing the ESR beam FOV, we expect that the added ionisation is originating from the equatorward side of the FOV, and then being transported poleward. This subjects nearly all of the FOV to increased ion-neutral collisions, which is evidenced 
by the fact the neutrals gained a significant amount of poleward momentum as soon as the PMAF began at 07:30 UT. This also holds true for the zonal velocities (panel 4), and is particularly interesting due to the transition in the IMF $\mathrm{B}_{\mathrm{y}}$ component. The response of the plasma to changes in $\mathrm{B}_{\mathrm{y}}$ is a well-studied area (e.g. Grocott et al., 2004), but the neutrals less so. For instance, McCormac et al. (1991) first observed a $\mathrm{B}_{\mathrm{y}}$ dependence on the neutral winds during sequential passes of the DE2 satellite, and Förster et al. (2008) generated statistical neutral wind patterns with a $\mathrm{B}_{\mathrm{y}}$ dependence using data from CHAMP. Plasma convection near the cusp responds rapidly to IMF changes in general, and a $\mathrm{B}_{\mathrm{y}}$ transition from negative to positive generates the westward to eastward velocity change (Rash et al., 1999) seen in this event. Because the neutral wind delay was substantially reduced as a result of enhanced precipitation, the neutrals respond to this $\mathrm{B}_{\mathrm{y}}$ change during a single SCANDI observation period.

In order for the neutrals to follow the convection, the ion drag force needs to remain in the same direction for an amount of time at least equal to the neutral wind delay timescale. Since the bulk motion of the neutrals is slow to respond to changes in the convection (hours) when there is no aurora, the time history of the convection plays a vital role (e.g. Aruliah et al., 1999) in determining the neutral wind structure before the PMAFs begin. As $B_{z}$ was negative for the first 1.5 hours, the plasma around noon MLT was broadly anti-sunward (i.e. poleward). As a result, the neutral winds shown in Figure 2 consistently has a poleward component that is enhanced significantly by the PMAF onset (07:30UT onwards in Figure 1, panel 5 and Figure 2). The neutrals maintaining a meridional component faster than the plasma from around 08:00UT onwards is potentially due to their high inertia in that direction, known as the neutral wind flywheel effect (Lyons et al., 1985).

As SCANDI co-rotates with Earth during the beginning of the event (anti-clockwise with respect to Figure 2), the lower latitude regions fell within the eastward return flow region of convection, hence the initial eastward neutral wind. When the PMAF began, the neutrals had not yet turned fully westward to match the direction of the plasma flow which had already responded to the $\mathrm{B}_{\mathrm{y}}$ transition. This is to be expected, as the time between the $\mathrm{B}_{\mathrm{y}}$ transition and PMAF onset is almost certainly much shorter than the initial neutral wind response time. In the SCANDI integration period following the start of the PMAF (07:30:05UT in Figure 2), the neutral flow in the vicinity of the aurora had turned westward, indicating a response timescale of at most 8 minutes. This appears to 
be much shorter than prior to the PMAF onset, as the neutral velocity both zonally and meridionally had been slow to accelerate to that of the plasma in the hour preceding. This is in agreement with results by Conde et al. (2018) and Zou et al. (2018), who saw similar timescales during auroral activity on the nightside. Once the aurora began, the neutral wind was at a similar velocity to the plasma flow zonally, and so changed direction almost instantly with it. Meridionally, the neutral wind immediately began accelerating up to the plasma velocity, matching it approximately 20 minutes later. The positive meridional direction is the direction of the solar driven pressure gradient force around the MLT's considered, but because the longitudinal distance covered was relatively small, there would be no significant change that could drive the acceleration seen. However, it could have contributed to maintaining the fast neutral wind mentioned earlier. The wind flywheel from 08:00-08:30 UT did not appear to enhance the meridional plasma velocity, but could have from 08:30 UT onwards. It also may have been partly responsible for the zonal velocities tracking close together.

Joule heating accounts for the majority of energy dissipated into the ionosphere from coupling to the magnetosphere (Knipp et al., 2004). It is therefore a vital parameter to calculate accurately for the purposes of space weather forecasting. It has previously been shown that the neutral winds can have a significant impact on modifying Joule heating (e.g. Billett et al., 2018), contrary to older studies which have assumed that the neutral velocity is negligible with respect to the plasma flow.

In the polar ionosphere, Joule heating is given by (e.g. Baker et al., 2004):

$$
Q_{j}=\Sigma_{P} E^{2}+2 \Sigma_{P} \mathbf{E}(\mathbf{u} \times \mathbf{B})+\Sigma_{P}(\mathbf{u} \times \mathbf{B})^{2}
$$

where $\mathbf{E}$ is the convection electric field (given by the electrostatic potential gradient), $\Sigma_{P}$ is the height integrated Pedersen conductivity, $\mathbf{B}$ is the magnetic field, and $\mathbf{U}$ is the neutral wind velocity. We only consider currents which are perpendicular to the magnetic field, as the electric field along the direction of $\mathbf{B}$ is typically very small (e.g. Lu et al., 1995). Here we obtain B using the International Geomagnetic Reference Field (IGRF) (Thébault et al., 2015).

In order to determine the Pedersen conductivity at a specific point within the allsky camera field, we utilise the equations set out by Hosokawa and Ogawa (2010) and Brekke (2012). The relevant neutral species densities are obtained from the NRLMSISE00 model (Picone et al., 2002), and the electron density from ESR. Once calculated at 
each altitude level, the Pedersen conductivity is then integrated over just F-region altitudes (to match the approximate emission altitudes of both the all-sky camera and SCANDI), defined here as between $200 \mathrm{~km}$ and $300 \mathrm{~km}$. This is also the altitude range where the neutral winds are approximately height-invariant due to their high viscosity (Dalgarno \& Smith, 1962).

Once a point conductivity measurement is derived, we may obtain a 2D extrapolation for each all-sky camera image by assuming a linear relationship between the Pedersen conductivity and $630 \mathrm{~nm}$ intensity (based on the work by Oyama et al., 2013). This is possible because in the F-region, the auroral emission intensity is proportional to the ion production rate (Kosch et al., 1998), which is in turn proportional to the electron density (Oyama et al., 2013) and conductivity (Brekke \& Moen, 1993). For each $630 \mathrm{~nm}$ all-sky image, the location of the ESR beam is found within the camera field of view and a corresponding intensity, I (in Rayleighs), and F-region integrated Pedersen conductivity, $\Sigma_{P}$, are paired. A least-squares linear fit is then applied to all pairs to determine a functional form of the conductivity with respect to intensity for the event presented in this study:

$$
\Sigma_{P}=0.0504+\left(I \cdot 2.5276 \times 10^{-5}\right)
$$

which has a reduced chi squared value of $\chi_{\nu}^{2}=1.6948$. Using this and equation $2,2 \mathrm{D}$ Joule heating images are produced using data from the all-sky camera, SuperDARN and SCANDI. These are shown in Figure 3 in the same format as Figure 2.

The Pedersen conductivity in the F-region is much smaller than in the E-region, and therefore so is the Joule heating. Typical enhancements are apparent in the 06:53:13, 07:08:12 and 07:16:00UT panels where the potential gradient was steep, and at 07:30:05 and 07:45:04UT in the location where the $630 \mathrm{~nm}$ emission (conductivity) was bright. Perhaps the most significant modifier of Joule heating however came from the neutral winds, which contrary to the electric field and conductivity, have both a reduction and enhancement effect per the second and third terms in equation 2. Joule heating is reduced when the neutrals flow in the direction of the plasma, which occurred in many of the panels shown in Figure 3. For instance, the $630 \mathrm{~nm}$ intensity enhancement was much lower at 07:30:05UT compared to 07:45:04UT, but the resultant Joule heating is comparable due to the neutral winds following the contours of convection more closely in the latter. Neutrals enhance Joule heating when they strongly oppose the plasma flow di- 

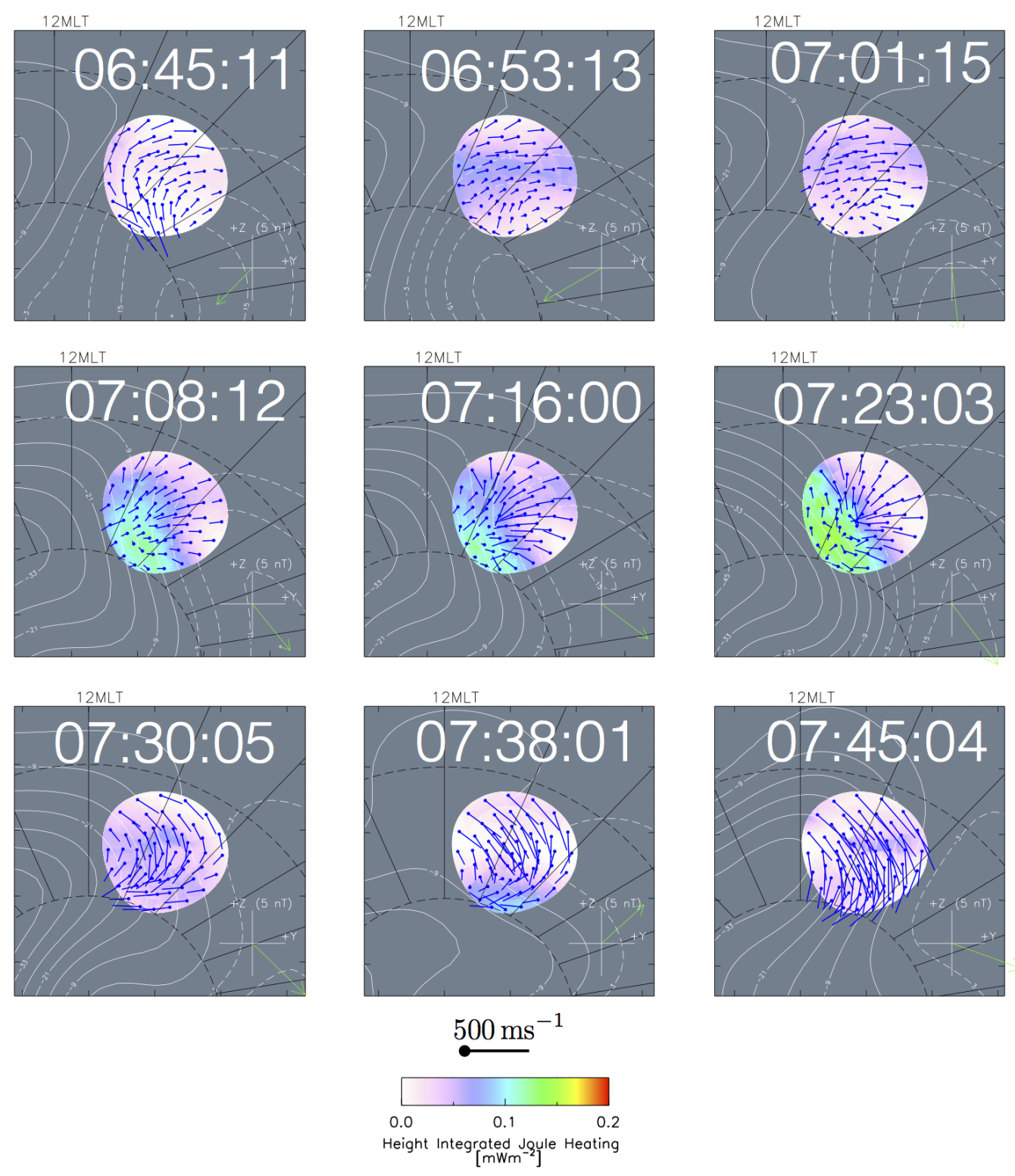

Figure 3. Same format as Figure 2, but showing the F-region integrated Joule heating rate.

rection, e.g. the most poleward region of the SCANDI FOV at 07:38:01UT and less obviously, the poleward regions at 07:08:12 and 07:16:00UT.

As ion-drag acts to pull the neutrals in the direction of the plasma convection, Joule heating was quickly reduced in the SCANDI FOV after the PMAF began at 07:30UT, even though the auroral brightness (and hence the conductivity) was much higher than it was before. Further evidence for a lack of Joule heating can be seen in the neutral temperatures shown in Figure 1, as $T_{n}$ began to decrease from around 07:45UT onwards. 
This illustrates the significant importance of the neutral winds in dampening Joule heating when the response timescale is reduced, as it was here.

Before the aurora began and when the neutrals were slow to transition into the plasma direction, Joule heating was enhanced due to greater ion-neutral friction. For example, this can be seen in the 07:08:12 and 07:16:00UT panels where the plasma had responded to the change in $\mathrm{B}_{\mathrm{y}}$ but the neutrals had not yet fully reconfigured. This is consistent with the neutral temperature increases between 06:50UT and 07:45UT, from $1150 \mathrm{~K}$ to $1450 \mathrm{~K}$; a fairly large increase that is indicative of strong Joule heating. Considering that the F-region neutral density is several orders of magnitude higher than the plasma density, it would thus require considerable energy to heat such a region (Emery et al., 1999).

\section{Summary}

We have examined the impact of the aurora on dayside F-region neutral winds near the cusp. From a 4-hour observation period above Svalbard, we note the following:

- The time for the neutrals to respond to changes in the ionospheric plasma convection while in the vicinity of poleward moving auroral forms was significantly reduced compared to non-aurorally active times (on the order of minutes, reduced from what appeared to be hours).

- Since the observations were made in the structured convection region of the dayside cusp and the response timescale was short, the thermospheric neutrals were influenced directly by changes in the IMF through dayside reconnection. For example, a quick east-west velocity change during the $\mathrm{B}_{\mathrm{y}}$ transition presented in this study.

- The strength of ion-neutral coupling is almost certainly related to the rate of thermospheric ionisation during auroral activity, as evidenced by very large electron density enhancements observed by ESR during the occurrence of poleward moving auroral forms.

- At F-region altitudes, the neutral wind velocity is a vital parameter when calculating Joule heating rates, in addition to the convection electric field and aurorally induced Pedersen conductivity. The reduced time for the neutral wind to be pulled into the orientation of plasma convection dampened Joule heating to the point where it was nearly entirely eliminated. 
We would like to emphasise that as a result of this study, we do not attempt to define a strict neutral wind delay time that can be indiscriminately applied to any thermosphereionosphere system due to its variable nature. For the particular event observed in this study however, the neutral wind appears to fully respond to a plasma flow change within 8 minutes when the ionosphere was aurorally active. Before the aurora began, the response timescale was at least 1 hour, but likely longer.

\section{Acknowledgments}

The authors acknowledge the use of data from SuperDARN, an international project made possible by the national funding agencies of Australia, Canada, China, France, Japan, South Africa, the United Kingdom and the United States of America. The UCL Scanning Doppler Imager (SCANDI) is maintained thanks to Dr Ian McWhirter, whose efforts are gratefully acknowledged. EISCAT is an international association supported by research organisations in China, Finland, Japan, Norway, Sweden, and the United Kingdom. The SuperDARN convection modelling was performed using RST4.1 (https://github.com/SuperDARN/rst). During this study, D.D.B was supported by the JSPS International Fellowships and Lancaster University, K. H was supported by JSPS Grants-in-Aid for Scientific Research 22340143 and 26302006, A.G and A.L.A were supported by NERC grant NE/P001556/1.

Data from this study can be accessed on figshare: https://bit.ly/37fRBAn

\section{References}

Aruliah, A. L., Griffin, E. M., Yiu, H.-C., McWhirter, I., \& Charalambous, A. (2010). SCANDI-an all-sky Doppler imager for studies of thermospheric spatial structure. Annales Geophysicae (09927689), 28(2).

Aruliah, A. L., Müller-Wodarg, I. C. F., \& Schoendorf, J. （1999). Consequences of geomagnetic history on the high-latitude thermosphere and ionosphere: Averages. Journal of Geophysical Research: Space Physics, 104(A12), 2807328088.

Baker, J., Zhang, Y., Greenwald, R. A., Paxton, L. J., \& Morrison, D. Height-integrated Joule and auroral particle heating in the night side high latitude thermosphere. Geophysical Research Letters, 31(9).

Billett, D. D., Grocott, A., Wild, J. A., Walach, M.-T., \& Kosch, M. J. Diurnal variations in global Joule heating morphology and magnitude due 
to neutral winds. Journal of Geophysical Research: Space Physics, 123(3), $2398-2411$

Billett, D. D., Wild, J. A., Grocott, A., Aruliah, A. L., Ronksley, A. M., Walach, M.-T., \& Lester, M. (2019). Spatially resolved neutral wind response times during high geomagnetic activity above svalbard. Journal of Geophysical Research: Space Physics.

Brekke, A. (2012). Physics of the upper polar atmosphere. Springer Science \& Business Media.

Brekke, A., \& Moen, J. (1993). Observations of high latitude ionospheric conductances. Journal of Atmospheric and Terrestrial Physics, 55(11-12), 14931512 .

Conde, M., Bristow, W. A., Hampton, D. L., \& Elliott, J. (2018). Multiinstrument studies of thermospheric weather above Alaska. Journal of Geophysical Research: Space Physics, 123(11), 9836-9861.

Conde, M., \& Smith, R. W. (1998). Spatial structure in the thermospheric horizontal wind above Poker Flat, Alaska, during solar minimum. Journal of Geophysical Research: Space Physics, 103(A5), 9449-9471.

Cooling, B. M. A., Owen, C. J., \& Schwartz, S. J. (2001). Role of the magnetosheath flow in determining the motion of open flux tubes. Journal of Geophysical Research: Space Physics, 106(A9), 18763-18775.

Dalgarno, A., \& Smith, F. J. (1962). The viscosity and thermal conductivity of atomic hydrogen. Proceedings of the Royal Society of London. Series A. Mathematical and Physical Sciences, 267(1330), 417-423.

Dungey, J. W. (1961). Interplanetary magnetic field and the auroral zones. Physical Review Letters, 6(2), 47.

Emery, B. A., Lathuillere, C., Richards, P. G., Roble, R. G., Buonsanto, M. J., Knipp, D. J., ... Niciejewski, R. (1999). Time dependent thermospheric neutral response tothe 2-11 november 1993 storm period. Journal of atmospheric and solar-terrestrial physics, 61(3-4), 329-350.

Fasel, G. J. (1995). Dayside poleward moving auroral forms: A statistical study. Journal of Geophysical Research: Space Physics, 100(A7), 11891-11905.

Fear, R. C., Fazakerley, A. N., Owen, C. J., \& Lucek, E. A. (2005). A survey of flux transfer events observed by Cluster during strongly northward IMF. Geophysi- 
cal research letters, 32(18).

Förster, M., Rentz, S., Köhler, W., Liu, H., \& Haaland, S. E. $\quad$ (2008). $\quad$ IMF dependence of high-latitude thermospheric wind pattern derived from CHAMP crass-track measurements. In Annales geophysicae: Atmospheres, hydrospheres and space sciences (Vol. 26, p. 1581).

Grocott, A., Badman, S. V., Cowley, S. W. H., Yeoman, T. K., \& Cripps, P. J. (2004). The influence of IMF By on the nature of the nightside high-latitude ionospheric flow during intervals of positive IMF Bz. European Geosciences Union (EGU).

Han, D.-S., Hietala, H., Chen, X.-C., Nishimura, Y., Lyons, L. R., Liu, J.-J., ... Yang, H.-G. (2017). Observational properties of dayside throat aurora and implications on the possible generation mechanisms. Journal of Geophysical Research: Space Physics, 122(2), 1853-1870.

Hosokawa, K., \& Ogawa, Y. (2010). Pedersen current carried by electrons in auroral D-region. Geophysical Research Letters, 37(18).

Jacchia, L. G. (1965). New static models of the thermosphere and exosphere with empirical temperature profiles. SAO special report, 313.

Joshi, P. P., H. Baker, J. B., Ruohoniemi, J. M., Makela, J. J., Fisher, D. J., Harding, B. J., ... Thomas, E. G. (2015). Observations of storm time midlatitude ion-neutral coupling using SuperDARN radars and NATION Fabry-Perot interferometers. Journal of Geophysical Research: Space Physics, 120(10), 8989-9003.

Knipp, D. J., Tobiska, W. K., \& Emery, B. A. (2004). Direct and indirect thermospheric heating sources for solar cycles 21-23. Solar Physics, 224(1-2), 495.

Kosch, M. J., Anderson, C., Makarevich, R. A., Carter, B. A., Fiori, R. A. D., Conde, M., ... Davies, T. (2010). First e region observations of mesoscale neutral wind interaction with auroral arcs. Journal of Geophysical Research: Space Physics, 115(A2).

Kosch, M. J., Cierpka, K., Rietveld, M. T., Hagfors, T., \& Schlegel, K. High-latitude ground-based observations of the thermospheric ion-drag time constant. Geophysical research letters, 28(7), 1395-1398.

Kosch, M. J., Hagfors, T., \& Schlegel, K. (1998). Extrapolating EISCAT pedersen conductances to other parts of the sky using ground-based tv auroral images. 
In Annales geophysicae (Vol. 16, pp. 583-588).

Lu, G., Richmond, A. D., Emery, B. A., \& Roble, R. G. (1995). Magnetosphereionosphere-thermosphere coupling: Effect of neutral winds on energy transfer and field-aligned current. Journal of Geophysical Research: Space Physics, 100(A10), 19643-19659.

Lyons, L. R., Killeen, T. L., \& Walterscheid, R. L. (1985). The neutral wind "flywheel" as a source of quiet-time, polar-cap currents. Geophysical Research Letters, 12(2), 101-104.

McCormac, F. G., Killeen, T. L., \& Thayer, J. P. (1991). The influence of IMF by on the high-latitude thermospheric circulation during northward IMF. Journal of Geophysical Research: Space Physics, 96(A1), 115-128.

McWilliams, K. A., Yeoman, T. K., \& Provan, G. (2000). A statistical survey of dayside pulsed ionospheric flows as seen by the cutlass finland HF radar. In Annales geophysicae (Vol. 18, pp. 445-453).

Murr, D. L., \& Hughes, W. J. (2001). Reconfiguration timescales of ionospheric convection. Geophysical Research Letters, 28(11), 2145-2148.

Oyama, S.-i., Watanabe, T., Fujii, R., Nozawa, S., Tsuda, T. T., et al.

$(2013)$ Layered conductance in the ionosphere estimated using data from a multiwavelength photometer at the European Incoherent Scatter radar site. Antarctic Record, 57(3), 339-356.

Pfaff, R. F. (2012). The near-earth plasma environment. Space Science Reviews, 168(1-4), 23-112.

Picone, J. M., Hedin, A. E., Drob, D. P. J., \& Aikin, A. C. (2002). NRLMSISE00 empirical model of the atmosphere: Statistical comparisons and scientific issues. Journal of Geophysical Research: Space Physics, 107(A12), SIA-15.

Rash, J. P. S., Rodger, A. S., \& Pinnock, M. (1999). HF radar observations of the high-latitude ionospheric convection pattern in the morning sector for northward IMF and motion of the convection reversal boundary. Journal of Geophysical Research: Space Physics, 104(A7), 14847-14866.

Rishbeth, H. (1972). Thermospheric winds and the F-region: A review. Journal of Atmospheric and Terrestrial Physics, 34(1), 1-47.

Ruohoniemi, J. M., \& Baker, K. B. (1998). Large-scale imaging of high-latitude convection with super dual auroral radar network HF radar observations. Journal 
of Geophysical Research: Space Physics, 103(A9), 20797-20811.

Ruohoniemi, J. M., Greenwald, R. A., Baker, K. B., Villain, J. P., \& McCready, M. A. (1987). Drift motions of small-scale irregularities in the high-latitude F region: An experimental comparison with plasma drift motions. Journal of Geophysical Research: Space Physics, 92(A5), 4553-4564.

Shepherd, S. G. (2014). Altitude-adjusted corrected geomagnetic coordinates: Definition and functional approximations. Journal of Geophysical Research: Space Physics, 119(9), 7501-7521.

Taguchi, S., Hosokawa, K., Ogawa, Y., Aoki, T., \& Taguchi, M. (2012). Double bursts inside a poleward-moving auroral form in the cusp. Journal of Geophysical Research: Space Physics, 117(A12).

Thébault, E., Finlay, C. C., Beggan, C. D., Alken, P., Aubert, J., Barrois, O., ... others (2015). International Geomagnetic Reference Field: the 12th generation. Earth, Planets and Space, 67(1), 79.

Thomas, E. G., \& Shepherd, S. G. (2018). Statistical patterns of ionospheric convection derived from mid-latitude, high-latitude, and polar SuperDARN HF radar observations. Journal of Geophysical Research: Space Physics, 123(4), 3196-3216.

Zou, Y., Nishimura, Y., Lyons, L., Conde, M., Varney, R., Angelopoulos, V., \& Mende, S. (2018). Mesoscale F region neutral winds associated with quasisteady and transient nightside auroral forms. Journal of Geophysical Research: Space Physics, 123(9), 7968-7984. 